\title{
Rehabilitation Considerations for Children Dependent on Long-Term Mechanical Ventilation
}

\author{
Helene M. Dumas \\ Research Center for Children with Special Health Care Needs, Franciscan Hospital for Children, 30 Warren Street, \\ Boston, MA 02135, USA \\ Correspondence should be addressed to Helene M. Dumas, hdumas@fhfc.org
}

Received 12 November 2012; Accepted 28 November 2012

Academic Editors: A. Ozcan Edeer and C. Zwingmann

Copyright ( 2012 Helene M. Dumas. This is an open access article distributed under the Creative Commons Attribution License, which permits unrestricted use, distribution, and reproduction in any medium, provided the original work is properly cited.

The purposes of this paper are as follows (1) to describe the prevalence, etiology, and care settings for children dependent on longterm mechanical ventilation (MV); (2) to provide a brief introduction to MV and weaning; (3) to explore health care utilization and cost of care; and, primarily, (4) to discuss the rehabilitation needs of children dependent on long-term MV including activities of daily living, mobility, communication, psychosocial needs, and recreation and leisure. Children with ventilator dependence are a growing segment of the population of children with special health care needs and often require rehabilitation services. MV is a form of life-saving technology that substitutes for or assists a child's respiratory efforts. Goals for use of MV vary and there are many combinations of MV elements that can obtain desirable results. No standards of care exist for the rehabilitation examination or interventions utilized for children with long-term MV dependence and it remains unclear what effect MV has on the achievement of developmental milestones, daily activities, and participation in daily life.

\section{Introduction}

Advances in obstetric care, neonatal intensive care, and pediatric critical care medicine have resulted in a growing population of children dependent on long-term mechanical ventilation (MV). Additionally, advances in medical technology are allowing children to live in to adulthood and the increasing use of portable ventilators is allowing children to be managed at home and in their communities [15]. While children dependent on long-term MV remain a small percentage of the overall group of children requiring rehabilitation services, studies indicate that this group of children continues to grow around the world [3,6-11].

Children dependent on long-term MV require rehabilitation services to address impairments, functional limitations, and participation restrictions in daily activities due to their injury, illness, or disease process. The purposes of this paper are as follows: (1) to describe the prevalence, etiology, and care settings for children dependent on longterm mechanical ventilation (MV); (2) to provide a brief introduction to MV and weaning; (3) to explore health care utilization and cost of care; and, primarily, (4) to discuss the rehabilitation needs of children dependent on long-term MV including activities of daily living, mobility, communication, psychosocial needs and recreation and leisure.

\section{Who Are the Children Dependent on Long-Term Mechanical Ventilation?}

Children dependent on MV present with varied diagnoses and clinical presentations and are united by their dependence on $\mathrm{MV}$ as a treatment modality for chronic respiratory insufficiency. The causes of chronic respiratory insufficiency in children have been grouped into the following categories: conditions which affect the lungs, lung parenchyma, and airway (e.g., bronchopulmonary dysplasia, tracheobronchomalacia); conditions which cause central dysregulation of breathing (e.g., ischemic encephalopathy, traumatic brain injury); and diseases or disorders of the chest wall and thorax, which affect the "respiratory pump" (e.g., spinal muscular atrophy, scoliosis) [9, 12-16]. Additionally, there may be combinations of the aforementioned conditions such as in genetic disorders that have associated pulmonary 
manifestations [17]. Children with chronic respiratory insufficiency who require long-term MV are medically complex and are at high risk for secondary illness and infection $[18,19]$, recurring hospitalizations $[18,20,21]$ and clinical compromise secondary to tracheostomy-related complications [21], and equipment failure [21-23].

A study in the state of Massachusetts in the United States found that the highest percentage of children requiring MV is no longer due to the chronic lung disease associated with premature birth but rather for reasons related to congenital and neurological disorders and neuromuscular diseases [3]. This shift is of particular importance to rehabilitation providers as children with congenital, neurological, and neuromuscular diagnoses are common diagnostic groups referred for rehabilitation services throughout the lifespan and it is thus, increasingly more likely that rehabilitation providers will encounter a child who is dependent on longterm MV. In a recent study of children requiring MV and admitted to one of six inpatient pulmonary rehabilitation programs in the Northeastern United States, $83 \%$ received rehabilitation services during their hospitalization and 50\% of those children discharged using ventilators required rehabilitation services after leaving the hospital [24].

Studies of incidence and prevalence are difficult to compare due to the varied methods of data collection, care settings, timeframes studied, and type of data collected. Table 1 provides a summary of studies from around the world describing children dependent on long-term MV.

\section{What Is Long-Term Mechanical Ventilation?}

Mechanical ventilation either substitutes for or assists a person's respiratory efforts. The principal benefits of MV for chronic respiratory insufficiency are improved gas exchange, decreased work of breathing and patient comfort [25]. By definition, an individual is considered to be a long-term ventilator user if mechanical ventilation is required for more than 6 hours per day for at least 3 weeks [26]. The decision to institute long-term mechanical ventilation is often made as a life-saving measure. Currently however, elective use of $\mathrm{MV}$ is increasing to preserve physiologic function and to improve quality of life. In many instances, for infants and children with chronic respiratory impairment, the clinical decision is made to take advantage of the growth and developmental potential of the lungs $[26,27]$ and to maximize developmental potential. Thus, the desired outcome for many, though not all, infants and young children is medical stability with adequate growth and healing of the lungs, and eventual withdrawal of the assisted ventilation. For others, it will remain an artificial means of life-supporting respiration throughout their life $[12,18,24]$.

Mechanical ventilation can be delivered invasively or noninvasively. Invasive positive pressure ventilation is sometimes referred to as conventional mechanical ventilation or traditional mechanical ventilation. Short-term invasive ventilation is delivered via endotracheal tube and may be used postsurgery, postinjury, following premature birth with underdeveloped lungs, and for acute respiratory failure due to illness [25]. For long-term MV, an endotracheal tube is no longer reasonable but rather a tracheostomy is required $[28,29]$. A tracheostomy is a surgically placed plastic or silicone tube placed between the third and fourth tracheal rings in the tracheal stoma to which the ventilator tubing is attached [28]. The size and shape of the tube are chosen based on the child's age, lung mechanics and upper airway resistance and speech needs [28-30]. In contrast, noninvasive positive pressure ventilation (NPPV) is delivered through an alternative interface such as a face mask or nasal prongs, and can be used short- or long-term [25].

There are many combinations of MV elements that can obtain desirable results, thus practices are far from uniform and scientific research is lacking [26, 31]. The type of mechanical ventilator and the optimal modes and settings for each child vary and are determined by the child's metabolic requirements, respiratory drive, and pulmonary mechanics [15, 32]; the age of the child; an understanding of the underlying disease process that precipitated respiratory failure; available equipment; knowledge of the current literature; previous experience of the clinical staff with specific types of machines; and site of care (e.g., intensive care unit (ICU), home environment) [32]. In general, ventilators are adjusted to maintain an oxygen saturation $>95 \%$ and a $\mathrm{CO}_{2}$ tension within the range of $35-45 \mathrm{mmHg}$ during wake and sleep [15]. Table 2 provides a brief description of ventilator classifications.

Rehabilitation providers should be familiar with ventilator alarms and emergency supplies and procedures for patients who are dependent on MV. Ventilator alarms signal high or low pressure changes, breathing problems, ventilator malfunction, and equipment or power failure. Additional equipment and supplies are required routinely and potentially, in case of emergency, and include: oxygen-may be needed to supplement air delivered by mechanical ventilation while tank oxygen should be available for emergencies; suctioning unit and supplies-needed to remove secretions from patient's airway, procedure requires training to avoid injury and infection and caregivers may be trained by healthcare professionals; humidification-warmed, humidified air to minimize secretions is needed for all patients receiving MV; power sources-most ventilators use household electrical current while battery back-up should be available in case of a power outage; tracheostomy tubes-spare tracheostomy tubes for routine changes and emergency decannulation must be readily available.

\section{Ventilator Weaning}

The transition to unassisted breathing (weaning from MV) is a complex issue. Weaning a child from the support of a mechanical ventilator is individualized and is accomplished in response to recovery from respiratory insufficiency, and as noted earlier, may not be a goal for all children $[12,18$, 24,33 ]. The primary assessment of weaning capability is to determine at what point the child is capable of maintaining adequate alveolar ventilation while breathing spontaneously. This requires that the child's neural control centers are 
TABLE 1: Reports of samples, etiology and care settings for children dependent on long-term MV.

\begin{tabular}{|c|c|c|c|c|c|}
\hline Country & $\begin{array}{c}\text { Study } \\
\text { timeframe }\end{array}$ & $\begin{array}{c}\text { Number and ages of } \\
\text { children studied }\end{array}$ & $\begin{array}{l}\text { Etiology/indication for } \\
\text { mechanical ventilation* }\end{array}$ & $\begin{array}{c}\text { Type of mechanical } \\
\text { ventilation }\end{array}$ & Care setting** \\
\hline Turkey-Istanbul [7] & $2001-2006$ & $\begin{array}{c}n=34 \\
4 \text { months to } 17 \text { years }\end{array}$ & $\begin{array}{c}\text { Neuromuscular } 18 \% \\
\text { Central dysregulation } 21 \% \\
\text { Airway/lung dysfunction } 62 \%\end{array}$ & $\begin{array}{c}\text { Invasive } 33 \% \\
\text { Non-invasive } 67 \%\end{array}$ & Home $100 \%$ \\
\hline Italy [9] & 2007 & $\begin{array}{c}n=362 \\
<17 \text { years of age }\end{array}$ & $\begin{array}{c}\text { Neuromuscular } 49 \% \\
\text { Central dysregulation } 25 \% \\
\text { Airway/lung dysfunction } 18 \%\end{array}$ & $\begin{array}{c}\text { Invasive } 41 \% \\
\text { Non-invasive } 59 \%\end{array}$ & Home $100 \%$ \\
\hline Japan [64] & 1996 & $\begin{array}{c}n=434 \\
<20 \text { years of age }\end{array}$ & $\begin{array}{c}\text { Neuromuscular 28\% } \\
\text { Central dysregulation 23\% } \\
\text { Airway/lung dysfunction 5\% } \\
\text { Other/unknown } 45 \%\end{array}$ & Unknown & $\begin{array}{l}\text { Hospital } 86 \% \\
\text { Home } 14 \%\end{array}$ \\
\hline Netherlands [65] & 1979-2009 & $\begin{array}{c}n=197 \\
<18 \text { years of age }\end{array}$ & $\begin{array}{c}\text { Neuromuscular } 66 \% \\
\text { Central dysregulation } 17 \% \\
\text { Airway/lung dysfunction } 6 \% \\
\text { Other } 11 \%\end{array}$ & $\begin{array}{c}\text { Invasive } 51 \% \\
\text { Non-invasive } 49 \%\end{array}$ & Home $100 \%$ \\
\hline Switzerland [8] & 2001 & $\begin{array}{c}n=32 \\
<16 \text { years of age }\end{array}$ & $\begin{array}{c}\text { Neuromuscular } 41 \% \\
\text { Central dysregulation } 47 \% \\
\text { Airway/lung dysfunction } 9 \% \\
\text { Other 3\% }\end{array}$ & $\begin{array}{c}\text { Invasive } 31 \% \\
\text { Non-invasive } 69 \%\end{array}$ & $\begin{array}{l}\text { Home } 94 \% \\
\text { Hospital 6\% }\end{array}$ \\
\hline Taiwan [66] & 1998-2006 & $\begin{array}{c}n=139 \\
3 \text { months to } 18 \text { years } \\
\text { of age }\end{array}$ & $\begin{array}{c}\text { Neuromuscular/Neurologic } 72 \% \\
\text { Airway/lung dysfunction } 14 \% \\
\text { Other } 14 \%\end{array}$ & $\begin{array}{c}\text { Invasive } 97 \% \\
\text { Non-Invasive } 3 \%\end{array}$ & $\begin{array}{l}\text { Hospital } 79 \% \\
\text { Home } 21 \% \\
\text { Death } n=37\end{array}$ \\
\hline United Kingdom [67] & 2008 & $\begin{array}{c}n=933 \\
<17 \text { years of age }\end{array}$ & $\begin{array}{c}\text { Neuromuscular 43\% } \\
\text { Central dysregulation 18\% } \\
\text { Airway/lung dysfunction 37\% }\end{array}$ & $\begin{array}{c}\text { Invasive } 23 \% \\
\text { Non-invasive } 77 \%\end{array}$ & $\begin{array}{l}\text { Home } 91 \% \\
\text { Hospital } 7 \% \\
\text { Unknown } 2 \%\end{array}$ \\
\hline United Kingdom [68] & 1999 & $\begin{array}{c}n=141 \\
<16 \text { years of age }\end{array}$ & $\begin{array}{c}\text { Neuromuscular 44\% } \\
\text { Central dysregulation } 24 \% \\
\text { Airway/lung dysfunction } 11 \% \\
\text { Other } 18 \%\end{array}$ & $\begin{array}{c}\text { Invasive } 48 \% \\
\text { Non-invasive } 52 \%\end{array}$ & $\begin{array}{l}\text { Home } 68 \% \\
\text { Hospital } 32 \%\end{array}$ \\
\hline $\begin{array}{l}\text { United } \\
\text { States-Massachusetts [3] }\end{array}$ & 2005 & $\begin{array}{c}n=197 \\
<22 \text { years of age }\end{array}$ & $\begin{array}{c}\text { Neuromuscular/neurologic 59\% } \\
\text { Airway/lung dysfunction 28\% } \\
\text { Other/unknown 13\% }\end{array}$ & $\begin{array}{c}\text { Invasive } 49 \% \\
\text { Non-invasive } 51 \%\end{array}$ & $\begin{array}{c}\text { Home care } 73 \% \\
\text { Hospital } 6 \% \\
\text { Unknown } 16 \%\end{array}$ \\
\hline United States-Utah [6] & 2004 & $\begin{array}{c}n=44 \\
<16 \text { years of age }\end{array}$ & $\begin{array}{c}\text { Neuromuscular 13\% } \\
\text { Central dysregulation 45\% } \\
\text { Airway/lung dysfunction } 41 \%\end{array}$ & Invasive $100 \%$ & Home $100 \%$ \\
\hline New Zealand [69] & $1991-2004$ & $n=160$ & $\begin{array}{c}\text { Neuromuscular 11\% } \\
\text { Central dysregulation 4\% } \\
\text { Airway/lung dysfunction 39\% } \\
\text { Other } 48 \%\end{array}$ & $\begin{array}{c}\text { Invasive } 3 \% \\
\text { Non-invasive } 97 \%\end{array}$ & Home $100 \%$ \\
\hline
\end{tabular}

* Etiologies may be combined as presented in study results.

**Home includes "community living" and "long-term care".

actively controlling the process, that the ventilatory pump is able to support the work required for breathing and that the lungs and airway are not severely compromised by disease $[12,34]$.

There exists no standard protocol for the discontinuation of long-term ventilator support yet the timing and prognosis for weaning is important for rehabilitation professionals to understand so that rehabilitation management may be directed appropriately. Weaning strategies for children in the post-acute setting are inherently different from those used in an ICU setting $[12,34]$. Most children in the ICU are ventilated via an endotracheal tube; while children admitted to post-acute settings or being cared for at home using invasive MV have tracheostomies in place to provide a longterm, stable airway. Proposed criteria for weaning readiness in the post-acute pediatric setting include: (1) no escalation in ventilator support within two days prior to weaning; (2) stable chest radiograph; (3) blood $\mathrm{PaCO}_{2}$ level not more than $10 \%$ above baseline; (4) blood $\mathrm{pH}$ within normal range; (5) supplemental $\mathrm{FiO}_{2}$ of 0.6 or lower; (6) stable blood pressure over the previous five to seven days; (7) heart rate no greater than $95 \%$ maximal normal for age; (8) tolerance of adequate nutrition; (9) absence of active infection, acute pain or other medical problems that might negatively impact 
TABLE 2: Mechanical ventilation classifications.

Non-invasive

Positive pressure ventilation

Airway pressure applied via face mask or nasal prongs; positive pressure beginning in the upper airway causes gas flow to the lungs until the ventilator breath is terminated; as the airway pressure drops to zero, elastic recoil of the chest accomplishes passive exhalation by pushing the tidal volume out.

Two types: Bi-level Positive Airway Pressure (BiPAP)—provides both inspiratory and expiratory positive airway pressure; Continuous Positive Airway pressure (CPAP) — provides only single level of airway pressure.

Negative pressure ventilation

Delivered via cuirass (shell); vacuum pump creates negative pressure in the chamber, resulting in reduced intrapulmonary pressure and allowing air flow into the lungs and expansion of the chest; when vacuum terminated, negative pressure applied to chest becomes zero, recoil of chest and lungs permits passive exhalation.

Invasive

Positive pressure ventilation

Airway pressure applied through an endotracheal tube or tracheostomy tube; gas flows along pressure gradient between upper airway and alveoli; achieved by delivering either a pre-determined volume or a set pressure to the lungs on a regular or a demand basis; PPV modes defined by inspiratory parameters.

Volume modes: Controlled Mechanical Ventilation (CMV)—100\% control by ventilator, patient has minimal or no respiratory effort); Assist Control Ventilation (ACV)—if patient fails to initiate breathing within prescribed time, ventilator triggers breath); Intermittent Mandatory Ventilation (IMV) — combination of spontaneous breathing and CMV as the ventilator provides a positive pressure breath at a pre-determined frequency); Synchronized Intermittent Mandatory Ventilation (SIMV) — patient triggers mandatory breath in assist mode thus synchronizing with own respiratory effort.

Pressure modes: Pressure Support Ventilation (PSV)—patient-triggered breath with a preset positive pressure thus using patient's own inspiratory timing and tidal volume; used for weaning; Pressure Control Ventilation (PCV)—time-initiated, pressure-limited and time-cycled mode; intended for patients fully dependent on MV; Pressure Assist Control Ventilation (PACV) —all breaths machine delivered at preset tidal volume; allows for patient triggering of breaths as described with PCV.

Positive End Expiratory Pressure (PEEP) — primary expiratory parameter; can be added to all above modes; used to increase functional residual capacity and distend alveoli.

the weaning process; and (10) reported understanding by the family/guardian and all health care providers of the desirability of weaning [12].

Weaning can be an arduous task both physiologically and psychologically, and it must be done with caution. Weaning may be enhanced by the improvement of cardiorespiratory strength and endurance, adequate nutrition, and overall health $[12,35,36]$. During periods of active weaning, a child's schedule of activities may need to be altered. It is imperative that there is coordination and communication between the medical and rehabilitation team as to the amount of physical exertion that can be tolerated safely. Both muscular and respiratory fatigue during this period of time must be avoided. In general, children may be weaned completely off $\mathrm{MV}$; advanced to portable equipment; progressed to milder levels of ventilation (e.g., reduced pressure support); or weaned to a less invasive mode of support (e.g., continuous positive airway pressure (CPAP)) $[12,18,24,37]$.

Minimizing dependence on mechanical ventilation promotes improved quality of life with a reduction in hospital stays, improved physical and mental health and increased social participation opportunities for children and their families [27, 38]. Despite the financial, clinical and psychosocial advantages of weaning children with ventilator dependency in a post-acute inpatient setting, only a few studies have reported outcomes on cohorts of children undergoing active weaning programs. In a 1995 study, 42\% of infants with
BPD were weaned from MV to CPAP and 29\% weaned to a tracheostomy with supplemental oxygen. However, only $9 \%$ of children with diagnoses other than BPD were weaned to a less restrictive form of support [18]. In another single site study from an inpatient pulmonary rehabilitation program in the United States, successful ventilator weaning was achieved during 30\% of the admission-discharge episodes with diagnosis (prematurity with BPD) and age (younger) being the strongest predictors of weaning success [33]. In a prospective multisite study over a one-year period, nearly half of the children who were dependent on MV 24 hours per day at admission to inpatient pulmonary rehabilitation no longer required MV at discharge. In addition, four children required only 12 or fewer hours per day of ventilator support at discharge [37]. Despite the home environment being a less closely monitored situation, there have been reports of children's dependence on MV being minimized while being cared for at home [39, 40].

\section{Environments of Care}

Infants in a neonatal intensive care unit (NICU) may be placed on MV because of lung or airway anomalies, neurological disorders affecting respiration, or disorders of the respiratory pump. A study by Vohr et al. [41] indicated that the length of time on MV in neonatal intensive care ranged from 16 to 40 days across multiple centers for infants who were born prematurely. Children in a pediatric intensive 
care unit may be placed on mechanical ventilation for postsurgical indications; due to a recent trauma, illness, or organ failure; or because of a history of chronic respiratory failure. Only a small percentage of these children will require longterm MV [3, 42]. Once the decision has been made to mechanically ventilate an infant or child for an extended length of time, immediate thoughts should be toward the long-term impact of a prolonged hospitalization and the alternative available care environments.

In recent years, the locus of inpatient care for children dependent on long-term MV has shifted from acute care hospital neonatal and pediatric intensive care units (ICUs) to "ventilator wards" in acute care hospitals [43-45] and postacute inpatient pulmonary rehabilitation programs $[18,24$, 46-48]. ICUs are referring children to rehabilitation units where they can spend longer periods of time at a lower financial cost. In the post-ICU environment, children may be stabilized on their ventilator, weaned from the ventilator, or weaned to a less invasive mode of ventilation $[18,24,33,46-$ 50]. Weaning ventilator support to the least invasive mode possible to optimize safe discharge home while providing a developmentally appropriate environment with necessary rehabilitation services appears to be an appropriate expectation for post-acute care. Parent-child interaction, parent education, and growth and development can be promoted along with the achievement of medical stability [13, 24, 51]. A limited number of rehabilitation facilities however, report admitting children who are ventilator dependent $[4,24,46-$ 48].

Whether fully weaned, weaned to fewer hours per day, or weaned to a less invasive mode of ventilation, the ultimate goal is to discharge children home or to community living. When medically stable on a ventilator suitable for nonhospital use and with appropriate caregiver support, children dependent on MV can be cared for at home and participate in community activities $[9,11,23,39,40,52,53]$. This option is dependent on many factors, but primarily on a stable airway, an oxygen requirement typically less than $40 \%$, a $\mathrm{PaCO}_{2}$ level not more than $10 \%$ above baseline, as well as an adequate nutritional intake to maintain growth and development [12].

While technologic advances in design, efficiency, and portability have contributed to an increase in use of MV outside the hospital environment, specific and careful hospital discharge planning is required [21, 50, 54, 55]. Barriers to discharge from the hospital exist, however. These barriers include the inability to recruit qualified home nursing staff; inadequate or delayed funding of home care resources; unsuitable housing; a limited number of capable family caregivers; and delays in obtaining the appropriate equipment $[50,54,56,57]$. It is imperative that the child's family or designated caregivers be involved in, and capable of learning, all aspects of the child's care [39, 40, 54-56, 58]. This care includes not only managing the ventilator and other equipment, but also being able to provide emergency medical care if the child experiences distress and most importantly, the ability to recognize signs of distress. The high degree of medical and technologic expertise required by parents or caregivers can be a tremendous drain on a family $[38,52,57-60]$. The critical nature of this type of family teaching goes beyond our normal expectations of the family unit, so caregivers may need extensive support from rehabilitation team members.

For children using MV at home, hospital readmissions are common following surgery or an acute respiratory illness $[20,28,61]$. Additional negative impacts of caring for a child at home on a ventilator include a burden on family life [62], financial consequences [63] and differences in ethical perception by the local community [62]. In addition, ventilation equipment must be managed by trained personnel, such as nurses, who may be a limited resource in many locations $[40,57,62,63]$.

\section{Considerations for Rehabilitation Professionals}

Regardless of the care setting, the rehabilitation professional working with infants, children and adolescents dependent on MV should have an understanding of the pathophysiology of chronic respiratory failure, the physiological conditions requiring $\mathrm{MV}$, the parameters of the ventilator machinery and emergency indicators. Rehabilitation providers should understand the type of mechanical ventilator being used by the child and whether the ventilator is doing all the work of breathing for the child or whether it is simply assisting the child with the number and/or depth of the breaths. Providers must also be aware of the clinical signs that may indicate that the child needs respiratory assistance and should familiarize themselves with the alarm systems of the ventilator, monitors that record oxygen saturation levels, heart and respiratory rates, and the emergency response procedures of the care setting.

As with any child referred for rehabilitation services, providers must first complete a comprehensive examination that includes a history, systems review and specific tests and measures. Because of the varying ages, diagnoses and prognoses, and intervention settings for children dependent on MV, tests and measures must be aimed at quantifying a child's functional skills that are most relevant to the child and family goals and individual care setting and include outcome measures related to cardiorespiratory endurance. A standardized developmental assessment or functional assessment tool can be used to quantify achievement of developmental milestones and/or changes in functional skills. No specific tools, however, have been recommended for children dependent on ventilators.

The multiple medical, emotional, educational and rehabilitative needs of the child with long-term ventilator dependence are beyond the expertise of a single provider and thus require the care and coordination of an interdisciplinary team. All rehabilitation providers can provide the child, family and other team members with information about the child's needs and strategies for participation within their school, home, and community environments. Table 3 outlines general rehabilitation goals and projected outcomes for children with long-term ventilator dependence in various care settings. 
TABLE 3: General rehabilitation goals and projected outcomes for children dependent on long-term mechanical ventilation.

\begin{tabular}{|c|c|}
\hline \multirow{9}{*}{ General goals } & Appropriate positioning for functional activity such as feeding, play, and fine motor activity \\
\hline & Activity tolerance/cardiorespiratory response adequate for activity \\
\hline & Developmental motor milestone achievement \\
\hline & Improved functional mobility \\
\hline & Maintenance or improvement of skin integrity and musculoskeletal alignment \\
\hline & Provision of adequate equipment (e.g., ADL equipment, seating and positioning, orthotics) \\
\hline & Functional communication \\
\hline & Adequate nutrition for health \\
\hline & Caregiver education \\
\hline \multicolumn{2}{|l|}{ Intended rehabilitation outcomes } \\
\hline \multirow{5}{*}{ Clinical outcomes } & Developmental skill attainment \\
\hline & Mobility independence \\
\hline & Independence with activities of daily living \\
\hline & Communication commensurate with cognitive ability \\
\hline & Health promotion to minimize dependence on ventilator and caregivers \\
\hline \multirow{3}{*}{ Prevention outcomes } & Reduction in need for additional intervention \\
\hline & Reduction in risk of impairment or impairment progression \\
\hline & Reduction in risk of re-hospitalization \\
\hline \multirow{3}{*}{ Child/family satisfaction outcomes } & Clinical proficiency of rehabilitation staff \\
\hline & Coordination of care is demonstrated \\
\hline & Access and availability of services acceptable \\
\hline
\end{tabular}

\section{Rehabilitation Needs}

Regardless of the environment of care, Children dependent on long-term mechanical ventilation have multiple rehabilitation needs that may be addressed by a myriad of rehabilitation care providers [49]. In addition to the child and family, the multidisciplinary rehabilitation care team for a child dependent on MV may include: the child's pediatrician; pediatric pulmonologists; other pediatric medical specialists (e.g., neurologist, physiatrist); respiratory therapists; nurses; physical and occupational therapists; speech-language pathologists, audiologists, nutritionists, social workers, durable medical equipment vendors, school personnel (teachers, aide, transportation provider, etc.) and case managers $[48,70]$.

All rehabilitation providers contribute expertise to address the primary goals of rehabilitation for children dependent on MV: to restore or maintain function and maximize independence. Rehabilitation providers also address acute and chronic medical needs, prevent secondary conditions, and promote health and wellness in addition to addressing needs related to activities of daily living, mobility and motor skills, cognition, communication, feeding and swallowing, nutrition, adaptive equipment, recreation and leisure activities, psychosocial concerns, and quality of life. A thorough examination and evaluation leading to a comprehensive plan for intervention with defined, measurable goals can lead to realistic and desired rehabilitation outcomes [49].

\section{Activities of Daily Living}

Activities of daily living (ADLs) include feeding, bathing, toileting, dressing, grooming home/environment management, and home, school, and work activities. ADLs vary by age, gender, care setting, disease limitations, and family expectations. Children dependent on mechanical ventilation face unique challenges in gaining and/or maintaining independence with these self-care activities, while providers are met with the challenge of how to intervene and measure changes in daily function $[49,51]$.

Studies examining activities of daily living that include children with dependence on long-term mechanical ventilation indicate a reduction in self-care independence and ability. In a study assessing the functional status of children across all types of Spinal Muscular Atrophy (SMA), all children with SMA type I were dependent on a ventilator and all required assistance with self-care activities [71]. In another study of 30 infants and children with varying diagnoses but who required oxygen and/or ventilator support upon admission to an inpatient pulmonary rehabilitation program, admission and discharge scores were noted to be on the lower half of the self-care continuum, indicating deficits in self-care function, despite increases in scores from admission to discharge [51]. The Functional Independence measure has been shown useful for detecting changes in function from admission to discharge for adults in pulmonary rehabilitation programs [72]. 
Independence with self-care activities for a child dependent on long-term MV will vary based on primary diagnosis, age, cognitive and physical impairments and may require modifications including adaptive equipment, assisted setup, altered procedures to conserve energy, and emergency problem-solving. It has been recommended that design improvements of medical technology for use at home are needed [73].

For infants and young children, feeding and playing are primary ADLs and dependence on caregivers is otherwise expected. Infants who are dependent on MV however, have experienced altered positioning, handling, and oral motor experiences. Oral aversion becomes a concern as oral intake may have been limited in the early weeks or early months of life. Often, oral intake is then inadequate to meet the caloric needs of a growing infant dependent on MV. In addition, infants are at risk for aspiration and as such, a nasogastric tube may be placed for short-term use [74]. Eventually, a gastrostomy tube may be needed to replace the nasogastric tube [75]. For older children, oral intake still may not be adequate to meet caloric and nutritional requirements and the continued use of a gastrotomy tube will be required [76].

For children with genetic and central nervous system disorders, bladder and/or bowel function may be impaired [77]. Regardless of the primary diagnosis, the use of mechanical ventilation may restricttoileting activities because of the restrictions of the ventilator tubing and environmental obstacles. As with any child or adult requiring environmental modifications, equipment such as grab bars, a raised or adapted toilet seat and/or a commode may be needed. Along with the child and family, rehabilitation team members can consult with durable medical equipment vendors to explore options for each of the child's care environments (e.g., school, home) for toileting.

Bathing options, similar to toileting options will be directed by the child's cognitive and physical impairments due to the underlying disease or disorder, the child's physical care environment as well as because of the child's ventilator dependence. Some children may spend short periods of time off of the ventilator and can bathe when off of the ventilator while other children may not.

Adaptive equipment is available for children who are physically able to independently dress or participate in dressing and grooming activities. Equipment such as longhandled reachers and extended handle hair brushes and combs are available. These devices allow rehabilitation providers and family members to encourage participation in activities of daily living and minimize energy expenditure for each child. It has been recommended that clothing that blocks the tracheostomy or access to any tubing be avoided. A myriad of home modifications and adaptive equipment options are available and should be individualized based on the child's needs and environment [78].

The percent of children who were ventilator dependent and engaging in daily home, school and work activities was documented by Lumeng et al. [79]. Results indicate that more than $97 \%$ of children who were ventilatordependent listened to music or watched television daily while approximately $74 \%$ attended school, and 53\% participated in computer activities. Frequent suctioning of the tracheostomy tube has been reported as a persistent interference with ADL independence $[80]$, promoting ongoing dependence on a caregiver.

\section{Mobility}

While children dependent on prolonged MV do not share a common diagnosis, there are many physical impairments common across diagnoses and conditions that may impact functional mobility and exercise participation and capacity. Skeletal muscle weakness, limited muscle-tendon flexibility, and skeletal and joint deformities due to a musculoskeletal or neuromuscular disorder or disuse, in addition to the cardiopulmonary impairments and potential cognitive limitations, consequently decrease functional mobility $[81,82]$.

In a study of 30 infants and children with varying diagnoses but who required oxygen and/or ventilator support upon admission to an inpatient pulmonary rehabilitation program, mean changes in functional mobility scores from admission to discharge were significant. Similar to the selfcare scores noted earlier in this same study, scores were at the low end of the scoring range, indicating limited mobility function [51].

Exercise training is a foundation of pulmonary rehabilitation programs for adults with chronic obstructive pulmonary disease (COPD), pulmonary hypertension and heart failure [83-85]. A review of mobility interventions for adults on prolonged MV revealed, however, that most studies introduced mobility intervention upon patient transfer to rehabilitation but not in the ICU during the earlier stages of illness and recovery. The review showed support for mobility interventions to improve weaning outcomes in patients on prolonged MV but a limited number of studies examine a variety of interventions (e.g., electrical stimulation, upper extremity exercise, inspiratory muscle training) and there is no report of improvement in functional mobility [81]. As with any diagnostic group, exercise limitations and restrictions should be determined prior to the start of an exercise program and children should be supervised closely to avoid musculoskeletal injury, excessive increases in heart and respiratory rate and dislodgement of tubing.

Ventilator dependence often dictates limited movement and mobility if the child must remain close to a non-mobile ventilator. Additionally, young children often spend little to no time in a prone position and this often only occurs during therapy. Exercise and activity in a prone position is useful as it provides an opportunity for strengthening of neck and shoulder girdle musculature. Rotational movements also are often constrained by the child's equipment limitations and/or impairments but should be encouraged as they are important components of mobility activities including creeping and ambulation. For children of all ages, upright positioning in sitting or standing is also important for physiological function and bone density and should be encouraged when developmentally and medically appropriate. Activities such as pull-to-stand and cruising may only 
occur in a crib if a child is in a hospital with limited opportunities for play time on the floor.

For children with ventilator dependence, functional mobility training may include bed mobility, transitional movements such as getting up from the floor or transfer training including getting in and out of bed and in and out of a wheelchair. There are no studies detailing motor or mobility interventions and their effectiveness for children dependent on prolonged MV. One could assume that the dependence on MV would have an impact on developmental motor skills if for no other reason than because of the child's restricted and constrained movement due to the ventilator and its tubing. It is unclear however, if there is a relationship between ventilator use, ventilator weaning outcomes and motor and mobility performance. As well, there are few reports of weaning outcomes that include motor/mobility skills. Reports of developmental motor outcome in survivors of bronchopulmonary dysplasia (BPD) are inconclusive as there is conflicting evidence demonstrating a relationship between the length of time a child is ventilated and developmental outcome. Several studies report that the shorter time an infant with BPD uses a ventilator, the better the developmental outcome [86-88]. Others however, show no significant correlation between duration of MV and overall developmental prognosis, hypothesizing that the impact of other medical complications (e.g., hypoxic episodes, low birthweight) have a greater effect on developmental outcome than MV [89].

In a recent case study report, achievement of independent ambulation while a child was using CPAP is reported. The progress made when an 18-month old with chronic lung disease and tracheobronchomalacia was provided a new CPAP device that allowed compressed air to be delivered via trachesotomy tube with extended tubing is described. It was hypothesized that the shorter, heavier tubing of the traditional CPAP device had severely restricted the child's mobility but application of the new CPAP device afforded the child the additional space to move (up to 10 meters) [90].

Ventilator settings may be influenced by the child's physical response in areas such as strength, functional skills and endurance, provided these findings are communicated to the medical care team. It has been noted that the observations and ongoing clinical assessment made by rehabilitation therapists can be critical factors in weaning decisions and these individuals can be a valuable resource in clinical decision making [91]. It has also been the experience of this author that therapy participation may be limited when children are being actively weaned from the ventilator. Infants may sleep more and older children often do not tolerate the same level of physical activity until they accommodate to the increased demands on their respiratory system. It is essential that the team coordinate the management of these children at all levels of their care. Additionally, it is essential that therapists be skilled in the assessment and monitoring of exercise capacity and limitations and that outcome measures reflect these parameters [92].

Appropriate equipment can minimize caregiver dependence and assist a child to attain independence with functional mobility. Orthoses may be needed to manage joint contractures, maintain joint flexibility, or provide proper alignment of the trunk, feet, legs, hands, or arms. For a child who may require a trunk orthosis secondary to weak or paralyzed axial musculature or those being treated for scoliosis, it is important that the orthosis allow for full rib cage expansion. Adaptive equipment may also be used to minimize the chance of secondary impairments due to the underlying disease process and/or immobility. Young children may require specialized adapted strollers with ventilator carrying capability. Older children may require manual or power wheelchairs adequately outfitted to transport a ventilator. The ventilator and other equipment must be safely secured to the seating system. Children who are independent ambulators may carry their ventilator in a traditional backpack, a rolling backpack, in a pushcart, or be accompanied by a caregiver who transports the ventilator using any of the listed options. For those children who require a wheelchair, multiple options are available for either manual or power wheelchairs and an experienced clinician and durable medical equipment vendor can help the child and family determine the safest, most energy efficient, and feasible seating and mobility system [93].

In addition to considering the functional mobility of children dependent on long-term MA, transporting children dependent on MV in a motor vehicle presents a challenge for caregivers. In a study by Lumeng et al. [79] examining quality of life of children who are ventilator dependent, it was reported that children rode in a car between zero and 30 times per month. In 1999, the American Academy of Pediatrics released guidelines for transporting children with special health care needs including recommendations for children with tracheostomies. These recommendations include use of a rear-facing care safety seat with a threepoint harness or a care safety seat with a five point harness and avoiding the use of a harness-tray/shield combination. The American Academy of Pediatrics has published a policy statement and guidelines for the transport of children with special health care needs. These guidelines include securing electrical equipment to the floor or seat of the vehicle [94]. In addition, when transporting a ventilator, it has been our typical practice for the child to have a spare tracheostomy tube, ambu bag, oxygen tank, portable suction unit with sterile catheters, and an external battery for the ventilator. More recent and specific guidelines can be found for many states and individual towns and counties within the United States including the use of battery power, tie-downs, and securing the ventilator in a car seat.

\section{Communication}

As noted earlier, children dependent on long-term MV have had a tracheostomy placed to provide a stable attachment for the ventilator tubing. Placement of a tracheostomy tube redirects the natural inspiratory and expiratory flow of air from the nose and oropharynx to the path of least resistance (the artificial opening of the tube) resulting in minimal airflow across the vocal folds. This diminished airflow reduces vocal 
intensity to inaudible levels, altering a child's ability to vocalize and negatively affects the development of expressive language skills in children [95].

Naturally, it would be expected that infants and young children with a tracheostomy and subsequent reduced vocalization miss out on many of the critical steps toward speech development and early forms of communication including cooing, babbling and crying. For the older child who has undergone tracheostomy placement, there is often a loss of the ability to communicate verbally. Reports indicate that tracheostomy affects speech and language development in children with and without neurological disorders. Established factors influencing speech and language development in children without neurological involvement include the child's age at the time of tracheostomy placement and the duration of the tracheostomy until decannulation [96].

Children with long-term MV via tracheostomy may need to use multiple methods of communication depending on their age, cognitive development and neurological status [96]. In a study examining quality of life for children using mechanical ventilation at home, the communication modalities of the 35 child participants were noted to be as follows: oral communication (71\%), oral communication combined with other modalities (9\%), eye blinking only $(6 \%)$, communication device (3\%), combination of communication modalities without oral communication $(3 \%)$, and other methods (9\%) [79].

In another study that included 35 children who were ventilator dependent and recruited to describe their health and quality of life, six children required the help of a caregiver to assist with communication, one child had no speech or established method of communication (parent read movement of lips), and the remaining 22 children had difficulty communicating, such as having speech that was affected by the ventilator and/or their tracheostomy [53].

Speech can be facilitated in patients with a tracheostomy tube who are breathing spontaneously by use of a talking tracheostomy tube, by using a cuff-down technique with finger occlusion of the proximal tracheostomy tube, and with the use of a cuff-down technique with a speaking valve [97]. A cuff is a soft balloon around the distal end of the tube that is inflated to provide an adequate seal to allow for mechanical ventilation.

Attachment of a one-way speaking valve to the external hub of the tracheostomy tube allows expiratory flow of air around the tube to instead exit up through the larynx and vocal folds rather than the tracheostomy tube promoting phonation. Improved verbal communication has been documented with the use of tracheostomy speaking valves in adults [97] and children [98]. In a study by Hull et al. [95], all 10 children who tolerated a speaking valve achieved phonation. Vocalizations included audible crying, nonspecific vocalizations, word approximations, single words, and short phrases.

A recent survey of speech-language pathologists in the United Kingdom indicated that the majority $(71 \%)$ were confident managing patients with a tracheostomy while still seeking professional development opportunities [99].

\section{Psychosocial Concerns}

Findings on the psychosocial impact of long-term MV for children and their families are important for all rehabilitation providers to consider regardless of role or care setting. Integrated, supportive services are required to help counter the challenges and distress endured by children and their families. Home ventilation offers a viable option for children's psychosocial development, social integration, and quality of life $[10,39,52]$. Many children who are ventilator-dependent can attend school and participate in family activities [39]. Unfortunately, negative consequences for families exist including a physical burden, emotional turmoil, and financial hardship [59,62, 100]. Time demands of care routines limit participation in employment and social opportunities for family caregivers.

Differences exist between family expectations and what professional care providers are able to provide [101]. Home nursing support, in particular night nursing, is important for the health and well-being of familial caregivers of children dependent on long-term MV [102]. Parents report regular disruption to their sleep [103] and the high demands related to the care of a child with long-term MV has been shown to be a significant risk factor for poor mental health outcomes of those mothers providing care at home [104]. The need for improved collaboration and communication between families and caregivers has also been cited as a source of stress for parents $[57,105]$. There continues to be a lack of trained care providers but sample training courses have been published to improve the quality of home care for children who are dependent on technology $[56,106]$.

\section{Recreation and Leisure Activities}

Exercise and physical activity are highly regarded as recreation and leisure activities to promote physical health and health-related quality of life for adults and children of all ages and abilities. Evidence suggests that children and youth with special health care needs have decreased physical activity compared to peers [107]. Rehabilitation providers are being encouraged to promote physical activity and extend children's rehabilitation services to include assessment and interventions for health-promotion and recommended levels of daily physical activity [108].

Resources to promote physical activity are needed and while recreation and physical activity options continue to grow for children with disabilities, children with dependence on long-term MV undoubtedly require additional accommodations. Few studies examine recreation and leisure activity participation of children dependent on long-term MV. Reports of participation in an ice skating program [109] and in a hospital-based fitness program are available [110]. Summer outdoor overnight camps are offered in multiple states throughout the United States of America [111]. In a 2001 study examining quality of life, children reported that their daily and monthly leisure activities included: watching television, listening to music, playing computer games, eating out, playing board games, going to the movies, and attending sporting events. The highest percentage of 
children participated in "at-home" activities such at watching television [79]. Rehabilitation providers can play a significant role in the development, adaptation, and evaluation of leisure and recreation programs for children dependent on long-term MV.

\section{Cost and Health Care Utilization}

Conclusions about cost and reimbursements for children dependent on long-term MV are difficult to draw based on limited research, distinctions in reimbursement policies, variations in care settings, delays in hospital discharge [40], and differences between countries. Costs for a child with dependence on long-term MV include equipment, hospital stays, ambulance transport, primary care medical services, medications, and other medical supplies [112]. Hospitalizations for children dependent on long-term MV require substantively greater inpatient resource use than other children with complex chronic conditions [113].

Edwards et al. [45] conducted a retrospective comparison of pediatric intensive care unit (PICU) and ventilator ward costs for 103 admissions in a US hospital between 2004 and 2007 in which children who were ventilator-dependent served as their own matched controls. The mean PICU cost was significantly more than the hospital ward cost. O'Brien and Dumas [47] compared the cost for post-acute hospitalizations by clinical group for the years 2010-2011 in a pediatric post-acute rehabilitation hospital in the Northeastern United States. The study's "Ventilator" Group had a significantly higher cost of hospitalization when compared to the following groups: "Active Rehabilitation" (children with traumatic brain injury, spinal cord injury, etc.), "Medically Complex" (children with chronic complex medical condition with one or more of the following: tracheostomy, gastrostomy; post-surgery (orthopedic, gastrointestinal), sepsis ruptured appendix, new onset or uncontrolled seizures, respiratory distress, dehydration, failure to thrive, malnutrition), and "Infants" (non-complex with diagnoses such as Neonatal Abstinence Syndrome). This cost was directly related to the extended length of stay for children in the Ventilator group.

In the United Kingdom, Noyes et al. [112] reported that home care including qualified nurses and 24-hour care was more expensive than a standard children's hospital ward, but less expensive than a long-term ventilation unit or an intensive care unit. Additional estimates are needed to provide families, payers, and providers with reasonable, evidence-based cost estimates for care in all settings.

\section{Future Research/Study}

Providers involved in pediatric rehabilitation programs are encouraged to participate in clinical research so that a better understanding of all of the rehabilitaiton needs of this clinically diverse population can be achieved. There is little research depicting the rehabilitation interventions or outcomes of children dependent on long-term MV. Research directed at determining effective program planning, program improvements, appropriate resource utilization, and settingspecific rehabilitation outcome expectations for infants, toddlers, and children dependent on mechanical ventilation is needed. Additional research questions may include the impact of rehabilitation interventions on the weaning process and the impact of rehabilitation interventions on quality of life outcomes for children and their families. The impact of ventilator dependence on motor development for infants, infant's tolerance to handling, children's tolerance to exercise, the effectiveness of adaptive equipment including ADL devices and speaking valves are additional examples of potential study for children dependent on long-term mechanical ventilation.

\section{Summary and Recommendations}

Children dependent on long-term MV present unique challenges to rehabilitation providers due to their medical complexity and need for life-sustaining equipment. This is a heterogeneous group connected only by their dependence on medical technology and not medical or rehabilitation diagnosis. Children with ventilator dependence are a growing segment of the population of children with special health care needs though infants with prematurity and chronic lung disease are no longer the most prevalent diagnostic group of children requiring mechanical ventilation.

Long-term mechanical ventilation is considered invasive and provided via a tracheostomy tube. Weaning from MV may be a goal for many children but there exists no standard protocol for the discontinuation of long-term ventilator support. Rehabilitation services may be provided in the hospital, in the child's home, and/or at school. Providers must be aware of the type and purpose of ventilator equipment and emergency indications and responses. It remains inconclusive what effect MV has on activities of daily living, achievement of motor milestones and functional mobility, communication and participation in recreation and leisure activities. The goals of rehabilitation intervention(s) should be flexible and adapted to meet the changing needs of the child, family and the environment as the child ages. Providers should also be able to provide current resources to children and their caregivers on recreational opportunities, healthcare options, and adaptive equipment alternatives.

The following case examples illustrate rehabilitation considerations for children dependent on long-term MV.

\section{Case Example Number 1}

Jack is a five-month-old boy with a diagnosis of chronic lung disease secondary to bronchopulmonary dysplasia. Jack was born at 28 weeks gestation weighing 970 g. Jack's comorbidities include a diaphragmatic hernia, gastrostomy tube placement at two months of age, and a Grade II intraventricular hemorrhage. Jack has been ventilator dependent on a positive pressure ventilator since birth. A tracheostomy tube was placed at two months of age due to the ongoing need for ventilation. Jack spent four months in a neonatal intensive care unit before transferring to a 
post-acute inpatient pulmonary rehabilitation program at a corrected age of two months.

The projected outcomes for Jack's transfer to an inpatient pulmonary rehabilitation program included elimination and/or reduction of impairment (lung disease), functional limitations (developmental delay in motor, communication and feeding skills), and disability (ability to participate in age-appropriate family and social roles) as well as health and wellness promotion for Jack and education for his family. Though Jack has been using a ventilator since birth, his prognosis for weaning appears favorable due to his age and diagnosis $[18,33,37]$.

Jack's post-acute inpatient rehabilitation team includes a pediatrician, physiatrist, nursing staff, physical, occupational and speech therapists, child-life specialist, nutritionist, social worker, and case manager. Jack's examination in the postacute setting included gathering a history from the medical record and initial team meeting, a systems review and specific tests and measures. For the physical and occupational therapists on Jack's team, the tests and measures include cardiorespiratory and sensory response to handling and positioning, joint flexibility, active movement against gravity, and motor skill achievement using the Bayley Scales of Infant and Toddler Development (Bayley-III) [114]. Jack's prognosis for motor skill achievement cannot be based on the existing literature examining the relationship between mechanical ventilation and motor skill achievement as the research is inconsistent. Historical and current clinical factors such as gestational age [115], birth weight [115117], Grade II intraventricular hemorrhage [116], previous therapeutic intervention $[118,119]$, response to handling and positioning, and current level of motor development however can help rehabilitation therapists determine a prognosis. Jack's intervention will include age-appropriate developmental activities and caregiver education in positioning for comfort, musculoskeletal alignment, and promotion of motor development skills. It is anticipated that Jack will receive physical and occupational therapy throughout his post-acute hospitalization and following discharge. Jack's speech therapy will focus on the promotion of interaction, facilitation of the development of receptive and expressive language skills and oral feeding as appropriate. The entire team led by the pediatrician and pulmonologist, case manager and social worker will plan for Jack's discharge when his inpatient pulmonary rehabilitation goals have been met.

\section{Case Example Number 2}

Molly is a ten-year-old girl with a diagnosis of T-8 myelodysplasia with Arnold Chiari Type II Malformation, mild cognitive and language dysfunction, and upper limb discoordination. Molly has been ventilator dependent since five years of age when her difficulty breathing on her own worsened. Molly lives at home with her parents and attends a private day school for children with special needs. Molly receives physical, occupational, and speech therapy at school to facilitate her participation in her educational program.
Molly receives physical therapy at home once per week to prevent secondary impairments and activity limitations and to promote participation in her home and community. When initially referred for home therapy, the physical therapist examination included a history and systems review, the application of tests and measures including goniometry, strength testing, and the Pediatric Evaluation of Disability Inventory [120] to assess her functional capabilities, level of independence, and equipment modification needs. The therapist familiarized herself with clinical signs that indicated the need for respiratory assistance such as suctioning of Molly's tracheostomy because of increased secretions, the alarm systems of the ventilator, and the monitors that record oxygen saturation levels, heart and respiratory rates, and the emergency response procedures established in Molly's home. Molly's prognosis for independent mobility was based on her motor level, upper extremity strength, and cognitive function and her prognosis for ventilator weaning was noted to be poor due to her diagnosis and age $[33,37]$.

Molly's physical therapy intervention at home included interventions such as therapeutic exercise and functional training, and prescription, application, and fabrication of devices and equipment for Molly's trunk orthosis, anklefoot orthoses, and manual and power wheelchairs. Molly's intervention also included patient-family instruction to maximize Molly's endurance, independence, and mobility within her home and in regard to Molly's transportation needs. It is anticipated that Molly and her family will continue to require physical therapist patient-related education, consultation with other care providers, and/or direct interventions throughout her lifespan to promote wellness and prevention and to minimize secondary complications due to growth, Molly's dependence on mechanical ventilation, and neuromuscular paralysis.

\section{References}

[1] T. D. Simon, J. Berry, C. Feudtner et al., "Children with complex chronic conditions in inpatient hospital settings in the United States," Pediatrics, vol. 126, no. 4, pp. 647-655, 2010.

[2] P. C. Van Dyck, M. D. Kogan, M. G. McPherson, G. R. Weissman, and P. W. Newacheck, "Prevalence and characteristics of children with special health care needs," Archives of Pediatrics and Adolescent Medicine, vol. 158, no. 9, pp. 884-890, 2004.

[3] R. J. Graham, E. W. Fleegler, and W. M. Robinson, "Chronic ventilator need in the community: a 2005 pediatric census of Massachusetts," Pediatrics, vol. 119, no. 6, pp. e1280-e1287, 2007.

[4] S. L. Peterson-Carmichael and I. M. Cheifetz, "The chronically critically ill patient: pediatric considerations," Respiratory Care, vol. 57, no. 6, pp. 993-1002, 2012.

[5] M. P. Donahoe, "Current venues of care and related costs for the chronically critically ill," Respiratory Care, vol. 57, no. 6, pp. 867-886, 2012.

[6] M. Gowans, H. T. Keenan, and S. L. Bratton, "The population prevalence of children receiving invasive home ventilation in Utah," Pediatric Pulmonology, vol. 42, no. 3, pp. 231-236, 2007. 
[7] S. Oktem, R. Ersu, Z. S. Uyan et al., "Home ventilation for children with chronic respiratory failure in Istanbul," Respiration, vol. 76, no. 1, pp. 76-81, 2008.

[8] M. Kamm, R. Burger, P. Rimenzsberger, A. Knoblauch, and Jürg Hammer, "Survey of children supported by long-term mechanical ventilation in Switzerland," Swiss Medical Weekly, vol. 131, no. 19-20, pp. 261-266, 2001.

[9] F. Racca, G. Berta, M. Sequi et al., "Long-term home ventilation of children in Italy: a national survey," Pediatric Pulmonology, vol. 46, no. 6, pp. 566-572, 2011.

[10] N. Salahuddin, K. Haider, S. J. Husain et al., "Outcome of home mechanical ventilation," Journal of the College of Physicians and Surgeons Pakistan, vol. 15, no. 7, pp. 387-390, 2005.

[11] A. Sovtic, P. Minic, M. Vukcevic, G. Markovic-Sovtic, M. Rodic, and M. Gajic, "Home mechanical ventilation in children is feasible in developing countries," Pediatrics International, vol. 54, no. 5, pp. 676-681, 2012.

[12] J. E. O’Brien, D. J. Birnkrant, H. M. Dumas et al., "Weaning children from mechanical ventilation in a post-acute care setting," Pediatric Rehabilitation, no. 4, pp. 365-372, 2006.

[13] G. B. Mallory and P. C. Stillwell, "The ventilator-dependent child: issues in diagnosis and management," Archives of Physical Medicine and Rehabilitation, vol. 72, no. 1, pp. 43$55,1991$.

[14] W. B. Wheeler, E. L. Maguire, S. C. Kurachek, J. G. Lobas, J. H. Fugate, and J. J. McNamara, "Chronic respiratory failure of infancy and childhood: clinical outcomes based on underlying etiology," Pediatric Pulmonology, vol. 17, no. 1, pp. 1-5, 1994.

[15] R. S. Amin and C. M. Fitton, "Tracheostomy and home ventilation in children," Seminars in Neonatology, vol. 8, no. 2, pp. 127-135, 2003.

[16] J. Allen, "Pulmonary complications of neuromuscular disease: a Respiratory mechanics perspective," Paediatric Respiratory Reviews, vol. 11, no. 1, pp. 18-23, 2010.

[17] B. A. Pletcher and N. L. Turcios, "Pulmonary complications of manifestations of genetic disorders," Paediatric Respiratory Reviews, vol. 13, pp. 2-9, 2012.

[18] R. Buschbacher, "Outcomes and problems in pediatric pulmonary rehabilitation," American Journal of Physical Medicine and Rehabilitation, vol. 74, no. 4, pp. 287-293, 1995.

[19] E. Monteverde, A. Fernández, R. Poterala et al., "Characterization of pediatric patients receiving prolonged mechanical ventilation," Pediatric Critical Care Medicine, vol. 12, no. 6, pp. e287-e291, 2012.

[20] D. G. Cushman, H. M. Dumas, S. M. Haley, J. E. O’Brien, and V. S. Kharasch, "Re-admissions to inpatient paediatric pulmonary rehabilitation," Pediatric Rehabilitation, vol. 5, no. 3, pp. 133-139, 2002.

[21] S. S. Kun, J. D. Edwards, S. L. D. Ward, and T. G. Keens, "Hospital readmission for newly discharged pediatric home mechanical ventilation patients," Pediatric Pulmonology, vol. 47, no. 4, pp. 409-414, 2012.

[22] M. Canlas-Yamsuan, I. Sanchez, M. Kesselman, and V. Chernick, "Morbidity and mortality patterns of ventilatordependent children in a home care program," Clinical Pediatrics, vol. 32, no. 12, pp. 706-713, 1993.

[23] D. Boroughs and J. A. Dougherty, "Decreasing accidental mortality of ventilator-dependent children at home: a call to action," Home Healthcare Nurse, vol. 30, no. 2, pp. 103-111, 2012.

[24] J. E. O’Brien, S. M. Haley, H. M. Dumas et al., "Outcomes of post-acute hospital episodes for young children requiring airway support," Developmental Neurorehabilitation, vol. 10, no. 3, pp. 241-247, 2007.

[25] I. M. Cheifetz, "Invasive and noninvasive pediatric mechanical ventilation," Respiratory Care, vol. 48, no. 4, pp. 442-453, 2004.

[26] B. J. Make, "Epidemiology of long-term ventilatory assistance," in Long-Term Mechanical Ventilation, N. S. Hill, Ed., vol. 1, pp. 1-18, Marcel Dekker, New York, NY, USA, 2001.

[27] P. Prabhakaran, W. Sasser, and S. Borasino, "Pediatric mechanical ventilation," Minerva Pediatrica, vol. 63, no. 5, pp. 411-424, 2011.

[28] P. K. Maheshwari, M. R. Khan, and J. Haque, "Elective tracheostomy in mechanically ventilated children," Journal of College of Physicians and Surgeons Pakistan, vol. 22, no. 6, pp. 414-415, 2012.

[29] T. Spentzas, M. Auth, P. Hess, M. Minarik, S. Storgion, and G. Stidham, "Natural course following pediatric tracheostomy," Journal of Intensive Care Medicine, vol. 25, no. 1, pp. 39-45, 2010.

[30] J. M. Graf, B. A. Montagnino, R. Hueckel, and M. L. McPherson, "Pediatric tracheostomies: a recent experience from one academic center," Pediatric Critical Care Medicine, vol. 9, no. 1, pp. 96-100, 2008.

[31] R. Branson, "Understanding and implementing advances in ventilator capabilities," Current Opinion in Critical Care, vol. 10, no. 1, pp. 23-32, 2004.

[32] J. M. Shneerson, "Home mechanical ventilation in children: techniques, outcomes and ethics," Monaldi Archives for Chest Disease, vol. 51, no. 5, pp. 426-430, 1996.

[33] V. S. Kharasch, S. M. Haley, H. M. Dumas, L. H. Ludlow, and J. E. O’Brien, "Oxygen and ventilator weaning during inpatient pediatric pulmonary rehabilitation," Pediatric Pulmonology, vol. 35, no. 4, pp. 280-287, 2003.

[34] A. G. Randolph, D. Wypij, S. T. Venkataraman et al., "Effect of mechanical ventilator weaning protocols on respiratory outcomes in infants and children: a randomized controlled trial," Journal of the American Medical Association, vol. 288, no. 20, pp. 2561-2568, 2002.

[35] D. R. Gracey and R. D. Hubmayr, "Weaning from long-term mechanical ventilation," in Long-Term Mechanical Ventilation, N. S. Hill, Ed., vol. 1, pp. 431-448, Marcel Dekker, New York, NY, USA, 2001.

[36] A. S. Graham and A. L. Kirby, "Ventilator management protocols in pediatrics," Respiratory Care Clinics of North America, vol. 12, no. 3, pp. 389-402, 2006.

[37] J. E. O'Brien, H. M. Dumas, S. M. Haley et al., "Ventilator weaning outcomes in chronic respiratory failure in children," International Journal of Rehabilitation Research, vol. 30, no. 2, pp. 171-174, 2007.

[38] J. K. Mah, J. E. Thannhauser, H. Kolski, and D. Dewey, "Parental stress and quality of life in children with neuromuscular disease," Pediatric Neurology, vol. 39, no. 2, pp. 102-107, 2008.

[39] R. L. Gilgoff and I. S. Gilgoff, "Long-term follow-up of home mechanical ventilation in young children with spinal cord injury and neuromuscular conditions," Journal of Pediatrics, vol. 142, no. 5, pp. 476-480, 2003.

[40] E. A. Edwards, M. O’Toole, and C. Wallis, "Sending children home on tracheostomy dependent ventilation: pitfalls and outcomes," Archives of Disease in Childhood, vol. 89, no. 3, pp. 251-255, 2004.

[41] B. R. Vohr, L. L. Wright, A. M. Dusick et al., "Center differences and outcomes of extremely low birth weight infants," Pediatrics, vol. 113, no. 4 I, pp. 781-789, 2004. 
[42] C. Traiber, J. P. Piva, C. C. Fritsher et al., "Profile and consequences of children requiring prolonged mechanical ventilation in three Brazilian pediatric intensive care units," Pediatric Critical Care Medicine, vol. 10, no. 3, pp. 375-380, 2009.

[43] M. Hanashiro, A. O. C. Franco, A. A. Ferraro, and E. J. Troster, "Care alternatives for pediatric chronic mechanical ventilation," Jornal de Pediatria, vol. 87, no. 2, pp. 145-149, 2011.

[44] I. U. Ambrosio, M. S. Woo, M. T. Jansen, and T. G. Keens, "Safety of hospitalized ventilator-dependent children outside of the intensive care unit," Pediatrics, vol. 101, no. 2, pp. 257259, 1998.

[45] J. D. Edwards, C. Rivanis, S. S. Kun, A. B. Caughey, and T. G. Keens, "Costs of hospitalized ventilator-dependent children: differences between a ventilator ward and intensive care unit," Pediatric Pulmonology, vol. 46, no. 4, pp. 356-361, 2011.

[46] V. S. Nelson, P. J. Dixon, and S. A. Warschausky, "Longterm outcome of children with high tetraplegia and ventilator dependence," The Journal of Spinal Cord Medicine, vol. 27, supplement 1, pp. S93-S97, 2004.

[47] J. E. O'Brien and H. M. Dumas, "Hospital length of stay, discharge disposition and reimbursement by clinical program group in pediatric post-acute rehabilitation," Journal of Pediatric Rehabilitation Medicine. In press.

[48] J. E. O’Brien, H. M. Dumas, S. M. Haley et al., "Clinical findings and resource use of infants and toddlers dependent on oxygen and ventilators," Clinical Pediatrics, vol. 41, no. 3, pp. 155-162, 2002.

[49] A. Jung, I. Heinrichs, C. Geidel, and R. Lauener, "Inpatient paediatric rehabilitation in chronic respiratory disorders," Paediatric Respiratory Reviews, vol. 13, no. 2, pp. 123-129, 2012.

[50] M. Katz-Leurer, E. Be'eri, and D. Zilbershtein, "Discharge of respiratory-compromised children after respiratory rehabilitation," Israel Medical Association Journal, vol. 8, no. 7, pp. 473-476, 2006.

[51] H. M. Dumas, E. L. Rosen, S. M. Haley, M. A. FragalaPinkham, P. Ni, and J. E. O’Brien, “Measuring physical function in children with airway support: a pilot study using computer adaptive testing," Developmental Neurorehabilitation, vol. 13, no. 2, pp. 95-102, 2010.

[52] G. Ottonello, I. Ferrari, I. M. G. Pirroddi et al., "Home mechanical ventilation in children: retrospective survey of a pediatric population," Pediatrics International, vol. 49, no. 6, pp. 801-805, 2007.

[53] J. Noyes, "Health and quality of life of ventilator-dependent children," Journal of Advanced Nursing, vol. 56, no. 4, pp. 392-403, 2006.

[54] J. Noyes, "Barriers that delay children and young people who are dependent on mechanical ventilators from being discharged from hospital," Journal of Clinical Nursing, vol. 11, no. 1, pp. 2-11, 2002.

[55] E. Jardine and C. Wallis, "Core guidelines for the discharge home of the child on long term assisted ventilation in the United Kingdom,” Thorax, vol. 53, no. 9, pp. 762-767, 1998.

[56] D. K. Tearl and J. H. Hertzog, "Home discharge of technology-dependent children: evaluation of a respiratorytherapist driven family education program," Respiratory Care, vol. 52, no. 2, pp. 171-176, 2007.

[57] S. Kirk and C. Glendinning, "Developing services to support parents caring for a technology-dependent child at home," Child: Care, Health and Development, vol. 30, no. 3, pp. 209-218, 2004.

[58] N. Bezruczko, S. P. Chen, C. D. Hill, and J. M. Chesniak, "Measurement of mothers' confidence to care for children assisted with tracheostomy technology in family homes," Journal of Applied Measurement, vol. 12, no. 4, pp. 339-357, 2011.

[59] K. W. K. Wang and A. Barnard, "Technology-dependent children and their families: a review," Journal of Advanced Nursing, vol. 45, no. 1, pp. 36-46, 2004.

[60] K. W. K. Wang and A. Barnard, "Caregivers' experiences at home with a ventilator-dependent child," Qualitative Health Research, vol. 18, no. 4, pp. 501-508, 2008.

[61] J. G. Berry, D. E. Hall, D. Z. Kuo et al., "Hospital utilization and characteristics of patients experiencing recurrent readmissions within children's hospitals," Journal of the American Medical Association, vol. 305, no. 7, pp. 682-690, 2011.

[62] F. A. Carnevale, E. Alexander, M. Davis, J. Rennick, and R. Troini, "Daily living with distress and enrichment: the moral experience of families with ventilator-assisted children at home," Pediatrics, vol. 117, no. 1, pp. e48-e60, 2006.

[63] H. Margolan, J. Fraser, and S. Lenton, "Parental experience of services when their child requires long-term ventilation. Implications for commissioning and providing services," Child: Care, Health and Development, vol. 30, no. 3, pp. 257264, 2004.

[64] Y. Sakakihara, T. Yamanaka, M. Kajii, and S. Kamoshita, "Long-term ventilator-assisted children in Japan: a national survey," Acta Paediatrica Japonica, vol. 38, no. 2, pp. 137-142, 1996.

[65] F. M. Paulides, F. B. Plötz, L. P. Verweij-van den Oudenrijn, J. P. van Gestel, and M. J. Kampelmacher, "Thirty years of home mechanical ventilation in children: escalating need for pediatric intensive care beds," Intensive Care Medicine, vol. 38, no. 5, pp. 847-852, 2012.

[66] S. H. Hsia, J. J. Lin, I. A. Huang, and C. T. Wu, "Outcome of long-term mechanical ventilation support in children," Pediatrics \& Neonatology, vol. 53, no. 5, pp. 304-308, 2012.

[67] C. Wallis, J. Y. Paton, S. Beaton, and E. Jardine, "Children on long-term ventilatory support: 10 years of progress," Archives of Disease in Childhood, vol. 96, no. 11, pp. 998-1002, 2011.

[68] E. Jardine, M. O’Toole, J. Y. Paton, and C. Wallis, "Current status of long term ventilation of children in the United Kingdom: questionnaire survey," British Medical Journal, vol. 318, no. 7179, pp. 295-299, 1999.

[69] E. A. Edwards, K. Hsiao, and G. M. Nixon, "Paediatric home ventilatory support: the Auckland experience," Journal of Paediatrics and Child Health, vol. 41, no. 12, pp. 652-658, 2005.

[70] D. S. Boroughs and J. Dougherty, "A multidisciplinary approach to the care of the ventilator-dependent child at home: a case study," Home Healthcare Nurse, vol. 28, no. 1, pp. 24-28, 2010.

[71] B. H. Y. Chung, V. C. N. Wong, and P. Ip, "Spinal muscular atrophy: survival pattern and functional status," Pediatrics, vol. 114, no. 5, pp. e548-e553, 2004.

[72] G. Montagnani, G. Vagheggini, E. P. Vlad, D. Berrighi, L. Pantani, and N. Ambrosino, "Use of the functional independence measure in people for whom weaning from mechanical ventilation is difficult," Physical Therapy, vol. 91, no. 7, pp. 1109-1115, 2011.

[73] A. Fex, A. C. Ek, and O. Söderhamn, "Self-care among persons using advanced medical technology at home," Journal of Clinical Nursing, vol. 18, no. 20, pp. 2809-2817, 2009. 
[74] S. B. Leder, K. E. Baker, and T. R. Goodman, "Dysphagia testing and aspiration status in medically stable infants requiring mechanical ventilation via tracheotomy," Pediatric Critical Care Medicine, vol. 11, no. 4, pp. 484-487, 2010.

[75] P. Minar, J. Garland, A. Martinez, and S. Werlin, "Safety of percutaneous endoscopic gastrostomy in medically complicated infants," Journal of Pediatric Gastroenterology and Nutrition, vol. 53, no. 3, pp. 293-295, 2011.

[76] E. C. Lewis, B. Connolly, M. Temple et al., "Growth outcomes and complications after radiologic gastrostomy in 120 children," Pediatric Radiology, vol. 38, no. 9, pp. 963-970, 2008.

[77] M. D. Leclair and Y. Héloury, "Non-neurogenic elimination disorders in children," Journal of Pediatric Urology, vol. 6, no. 4, pp. 338-345, 2010.

[78] J. C. Haffner and S. J. Schurman, "The technology-dependent child," Pediatric Clinics of North America, vol. 48, no. 3, pp. 751-764, 2001.

[79] J. C. Lumeng, S. A. Warschausky, V. S. Nelson, and K. Augenstein, "The quality of life of ventilator-assisted children," Pediatric Rehabilitation, vol. 4, no. 1, pp. 21-27, 2001.

[80] T. Asano, H. Enokido, O. Fujino, and K. Hashimoto, "Improvement in daily activities using a portable ventilator in a patient with spondyloepiphyseal dysplasia congenita," Pediatrics International, vol. 43, no. 3, pp. 316-318, 2001.

[81] J. Choi, F. J. Tasota, and L. A. Hoffman, "Mobility interventions to improve outcomes in patients undergoing prolonged mechanical ventilation: a review of the literature," Biological Research for Nursing, vol. 10, no. 1, pp. 21-33, 2008.

[82] U. J. Martin, "Whole-body rehabilitation in long-term ventilation," Respiratory Care Clinics of North America, vol. 8, no. 4, pp. 593-609, 2002.

[83] S. Singh, S. Harrison, L. Houchen, and K. Wagg, "Exercise assessment and training in pulmonary rehabilitation for patients with COPD," European Journal of Physical and Rehabilitation Medicine, vol. 47, no. 3, pp. 483-497, 2011.

[84] D. Mereles, N. Ehlken, S. Kreuscher et al., "Exercise and respiratory training improve exercise capacity and quality of life in patients with severe chronic pulmonary hypertension," Circulation, vol. 114, no. 14, pp. 1482-1489, 2006.

[85] T. Troosters and H. V. Remoortel, "Pulmonary rehabilitation and cardiovascular disease," Seminars in respiratory and critical care medicine, vol. 30, no. 6, pp. 675-683, 2009.

[86] M. Thomas, A. Greenough, and M. Morton, "Prolonged ventilation and intact survival in very low birth weight infants," European Journal of Pediatrics, vol. 162, no. 2, pp. 65-67, 2003.

[87] S. F. Jeng, K. I. T. Yau, H. F. Liao, L. C. Chen, and P. S. Chen, "Prognostic factors for walking attainment in very lowbirthweight preterm infants," Early Human Development, vol. 59, no. 3, pp. 159-173, 2000.

[88] E. A. Gaillard, R. W. I. Cooke, and N. J. Shaw, "Improved survival and neurodevelopmental outcome after prolonged ventilation in preterm neonates who have received antenatal steroids and surfactant," Archives of Disease in Childhood, vol. 84, no. 3, pp. F194-F196, 2001.

[89] J. M. Luchi, F. C. Bennett, and J. C. Jackson, "Predictors of neurodevelopmental outcome following bronchopulmonary dysplasia," American Journal of Diseases of Children, vol. 145, no. 7, pp. 813-817, 1991.

[90] W. Dieperink, J. F. Goorhuis, W. de Weerd, A. Hazenberg, J. G. Zijlstra, and M. W. N. Nijsten, "Walking with continuous positive airway pressure," European Respiratory Journal, vol. 27, no. 4, pp. 853-855, 2006.
[91] G. J. Criner, "Care of the patient requiring invasive mechanical ventilation," Respiratory Care Clinics of North America, vol. 8, no. 4, pp. 575-592, 2002.

[92] H. M. Dumas, M. A. Fragala-Pinkham, E. L. Rosen et al., "Cardiorespiratory response during physical therapist intervention for infants and young children with chronic respiratory insufficiency," Pediatric Physical Therapy. In press.

[93] L. E. Driver, V. S. Nelson, and S. A. Warschausky, The Ventilator-Assisted Child: A Practical Resource Guide, The Psychological Corporation, San Antonio, Tex, USA, 1997.

[94] American Academy of Pediatrics and Committee on Injury and Poison Prevention, "Transporting children with special health care needs (RE9852)," Pediatric, vol. 104, no. 4, pp. 988-992, 1999.

[95] E. M. Hull, H. M. Dumas, R. A. Crowley, and V. S. Kharasch, "Tracheostomy speaking valves for children: tolerance and clinical benefits," Pediatric Rehabilitation, vol. 8, no. 3, pp. 214-219, 2005.

[96] D. Jiang and G. A. J. Morrison, "The influence of long-term tracheostomy on speech and language development in children," International Journal of Pediatric Otorhinolaryngology, vol. 67, supplement 1, pp. S217-S220, 2003.

[97] D. R. Hess, "Facilitating speech in the patient with a tracheostomy," Respiratory Care, vol. 50, no. 4, pp. 519-525, 2005.

[98] J. Fraser, A. Pengilly, and Q. Mok, "Long-term ventilatordependent children: a vocal profile analysis," Pediatric Rehabilitation, vol. 2, no. 2, pp. 71-75, 1998.

[99] E. Ward, T. Morgan, S. McGowan, A. L. Spurgin, and M. Solley, "Preparation, clinical support, and confidence of speechlanguage therapists managing clients with a tracheostomy in the UK," International Journal of Language \& Communication Disorders, vol. 47, no. 3, pp. 322-332, 2012.

[100] J. Hammer, "Home mechanical ventilation in children: indications and practical aspects," Schweizerische Medizinische Wochenschrift, vol. 130, no. 49, pp. 1894-1902, 2000.

[101] K. Dybwik, T. Tollåli, E. W. Nielsen, and B. S. Brinchmann, "Fighting the system: families caring for ventilatordependent children and adults with complex health care needs at home," BMC Health Services Research, vol. 11, article no. 156, 2011.

[102] L. J. Meltzer, D. S. Boroughs, and J. J. Downes, "The relationship between home nursing coverage, sleep, and daytime functioning in parents of ventilator-assisted children," Journal of Pediatric Nursing, vol. 25, no. 4, pp. 250-257, 2010.

[103] J. Heaton, J. Noyes, P. Sloper, and R. Shah, "Families' experiences of caring for technology-dependent children: a temporal perspective," Health and Social Care in the Community, vol. 13, no. 5, pp. 441-450, 2005.

[104] P. A. Kuster and L. K. Badr, "Mental health of mothers caring for ventilator-assisted children at home," Issues in Mental Health Nursing, vol. 27, no. 8, pp. 817-835, 2006.

[105] M. E. O’Brien and C. B. Wegner, "Rearing the child who is technology dependent: perceptions of parents and home care nurses," Journal for Specialists in Pediatric Nursing, vol. 7, no. 1, pp. 7-15, 2002.

[106] D. Boroughs and J. A. Dougherty, "Care of technologydependent children in the home," Home Healthcare Nurse, vol. 27, no. 1, pp. 37-42, 2009.

[107] K. Feehan, M. E. O’Neil, D. Abdalla et al., "Factors influencing physical activity in children and youth with special health care needs: a pilot study," International Journal of Pediatrics, vol. 2012, Article ID 583249, 11 pages, 2012. 
[108] G. Dwyer, L. Baur, J. Higgs, and L. Hardy, "Promoting children's health and well-being: broadening the therapy perspective," Physical and Occupational Therapy in Pediatrics, vol. 29, no. 1, pp. 27-43, 2009.

[109] M. A. Fragala-Pinkham, H. M. Dumas, M. Boyce, C. Y. Peters, and S. M. Haley, "Evaluation of an adaptive ice skating programme for children with disabilities," Developmental Neurorehabilitation, vol. 12, no. 4, pp. 215-223, 2009.

[110] M. A. Fragala-Pinkham, S. M. Haley, J. Rabin, and V. S. Kharasch, "A fitness program for children with disabilities," Physical Therapy, vol. 85, no. 11, pp. 1182-1200, 2005.

[111] S. Krcmar, "Room to breathe," RT: for Decision Makers in Respiratory Care, Allied Media, 2006.

[112] J. Noyes, C. Godfrey, and J. Beecham, "Resource use and service costs for ventilator-dependent children and young people in the UK," Health and Social Care in the Community, vol. 14, no. 6, pp. 508-522, 2006.

[113] B. D. Benneyworth, A. Gebremariam, S. J. Clark, T. P. Shanley, and M. M. Davis, "Inpatient health care utilization for children dependent on long-term mechanical ventilation," Pediatrics, vol. 127, no. 6, pp. e1533-e1541, 2011.

[114] N. Bayley, Bayley Scales of Infant Development, Psychological Corporation, San Antonio, Tex, USA, 3rd edition, 2005.

[115] A. Valcamonico, P. Accorsi, C. Sanzeni et al., "Mid- and longterm outcome of extremely low birth weight (ELBW) infants: an analysis of prognostic factors," Journal of Maternal-Fetal and Neonatal Medicine, vol. 20, no. 6, pp. 465-471, 2007.

[116] K. Patra, D. Wilson-Costello, H. G. Taylor, N. MercuriMinich, and M. Hack, "Grades I-II intraventricular hemorrhage in extremely low birth weight infants: effects on neurodevelopment," Journal of Pediatrics, vol. 149, no. 2, pp. 169-173, 2006.

[117] E. C. Cameron and V. Maehle, "Comparison of active motor items in infants born preterm and infants born full term," Pediatric Physical Therapy, vol. 18, no. 3, pp. 197-203, 2006.

[118] E. C. Cameron, V. Maehle, and J. Reid, "The effects of an early physical therapy intervention for very preterm, very low birth weight infants: a randomized controlled clinical trial," Pediatric Physical Therapy, vol. 17, no. 2, pp. 107-119, 2005.

[119] R. Lekskulchai and J. Cole, "Effect of a developmental program on motor performance in infants born preterm," Australian Journal of Physiotherapy, vol. 47, no. 3, pp. 169176, 2001.

[120] S. M. Haley, W. J. Coster, L. H. Ludlow, J. T. Haltiwanger, and P. A. Andrellos, Pediatric Evaluation of Disability Inventory: Development, Standardization and Administration Manual, Trustees of Boston University, Boston, Mass, USA, 1992. 


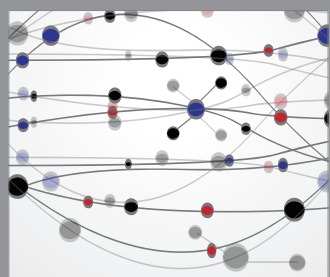

The Scientific World Journal
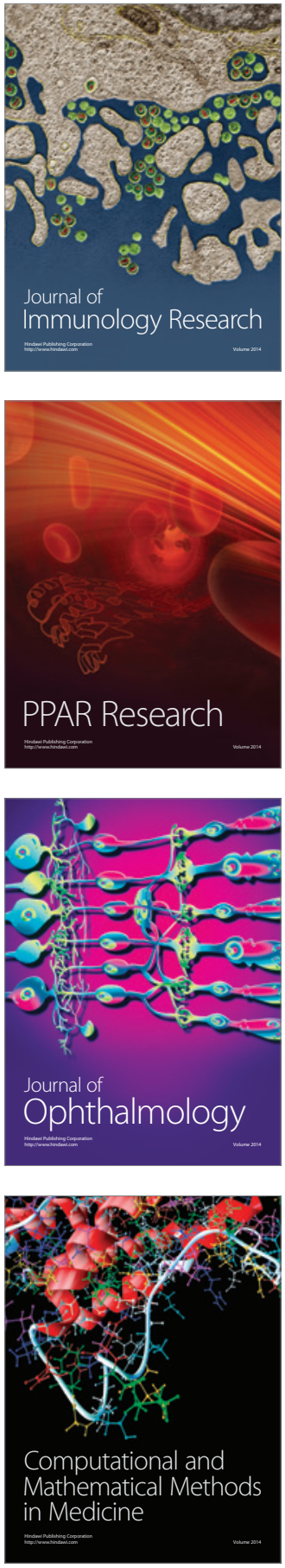

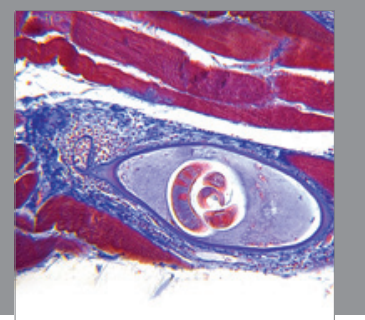

Gastroenterology

Research and Practice
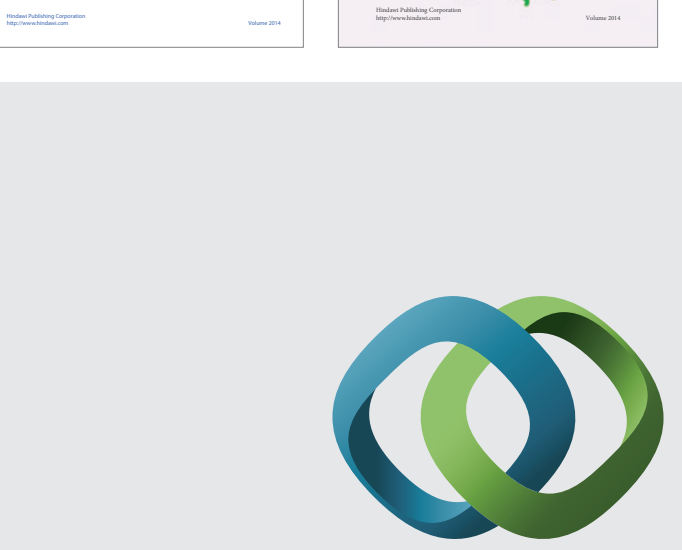

\section{Hindawi}

Submit your manuscripts at

http://www.hindawi.com
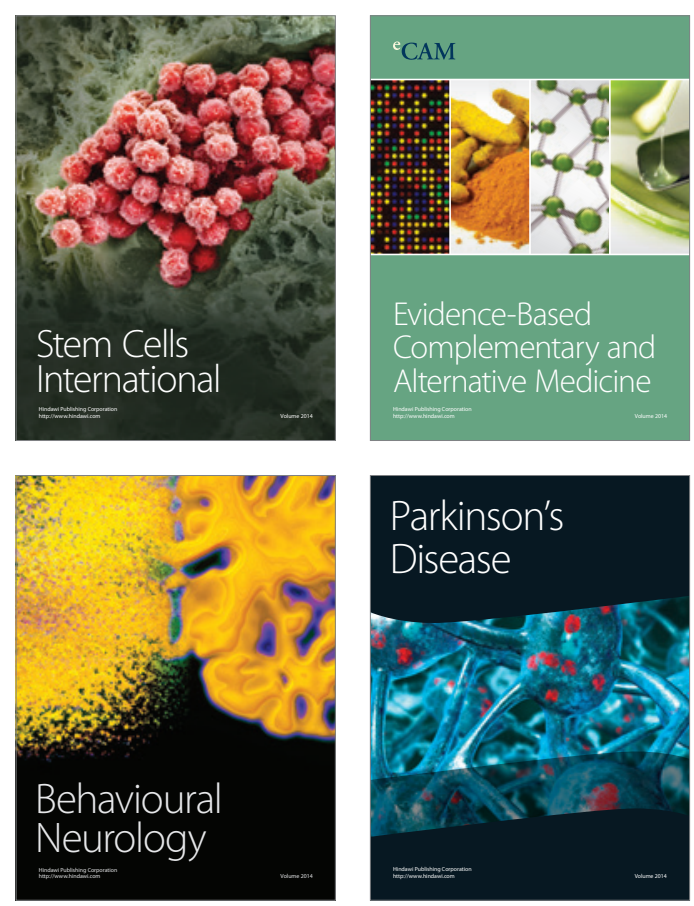

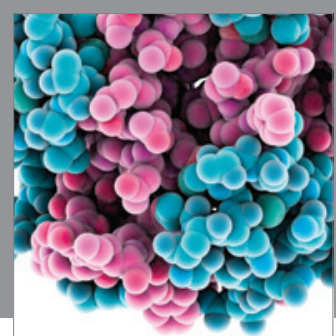

Journal of
Diabetes Research

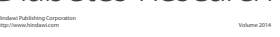

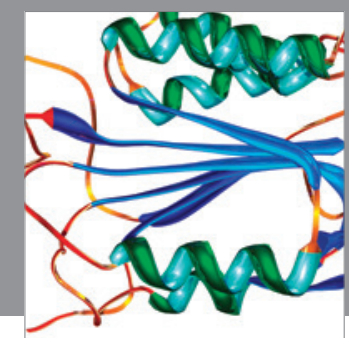

Disease Markers
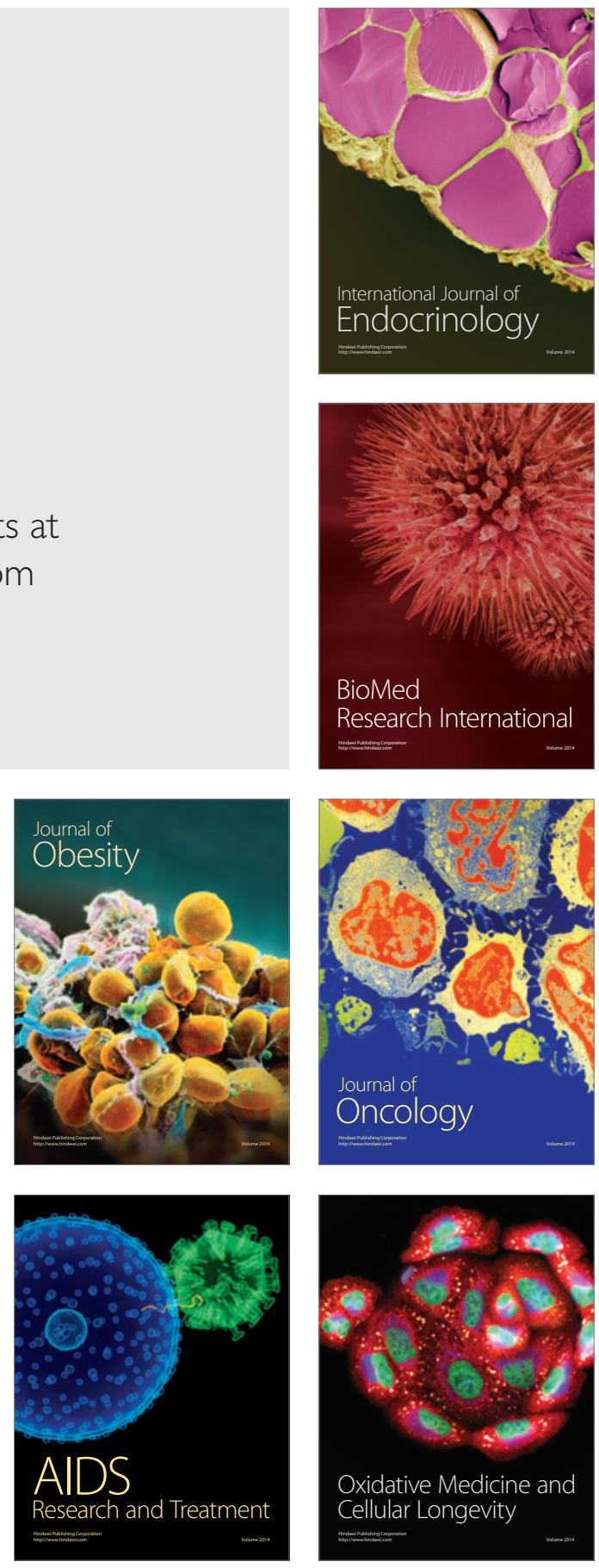